\title{
Impact of the Community-Based Active Monitoring Program on the Long Term Care Services Use and In-Patient Admissions of the Over-74 Population
}

\author{
Maria Cristina Marazzi' ${ }^{1}$ Maria Chiara Inzerilli2 ${ }^{2}$ Olga Madaro ${ }^{3}$, Leonardo Palombi4, \\ Paola Scarcella ${ }^{4}$, Stefano Orlando ${ }^{3}$, Massimo Maurici ${ }^{4}$, Giuseppe Liotta ${ }^{*}$ \\ ${ }^{1}$ LUMSA University, Rome, Italy \\ ${ }^{2}$ Municipality of Rome, Rome, Italy \\ ${ }^{3}$ Community of Sant'Egidio, Long Live the Elderly Program, Rome, Italy \\ ${ }^{4}$ Dept. of Biomedicine and Prevention, University of Rome "Tor Vergata", Rome, Italy \\ Email: "giuseppe.liotta@uniroma2.it
}

Received 14 September 2015; accepted 9 November 2015; published 13 November 2015

Copyright (C) 2015 by authors and Scientific Research Publishing Inc.

This work is licensed under the Creative Commons Attribution International License (CC BY).

http://creativecommons.org/licenses/by/4.0/

(c) $\underset{\mathrm{EY}}{\mathrm{i}}$ Open Access

\begin{abstract}
Introduction: Social isolation increases in the over-74 population and it is a risk factor for death and Long Term Care (LTC) use. In order to prevent the negative consequences of social isolation on this population community interventions focused on strengthening the social network should be intensified. The aim of this paper is to describe the impact on health care use of a Communitybased pro-Active Monitoring Program (CAMP) providing phone monitoring to all the clients and home visits according to the individual's needs. Methodology: In order to provide an evaluation of the program outcomes, the rates of clients' hospitalization and admissions to Long Term Care facilities during 2011 have been assessed. The observed rates have been compared with expected ones calculated on available information for similar population. A cost-analysis has been also carried out to analyze the program sustainability. Results: The studied sample is made up by 1408 over-74 citizens followed up during 2011 in Rome (Italy) by CAMP. The cumulative observation time was $1362 \mathrm{p} / \mathrm{y} ; 61$ individuals died during 2011 (death rate 4.3\%). The hospital admission rate observed among CAMP's clients was 254\%o (357/1408; CL95\% $\pm 91 \%$ ), lower than the $282 \%$ o reported for the over-74 population of Rome. This translates into 39 averted hospitalization. The LTC admission rate is also reduced among CAMP's clients $(9 / 1,408,6.6 \%$ CL95\% $\pm 0.8 \%$ vs. 9.7\%o reported for a comparable sample); it translates into 4 averted LTC admissions. The averted cost
\end{abstract}

*Corresponding author.

How to cite this paper: Marazzi, M.C., et al. (2015) Impact of the Community-Based Active Monitoring Program on the Long Term Care Services Use and In-Patient Admissions of the Over-74 Population. Advances in Aging Research, 4, 187-194. http://dx.doi.org/10.4236/aar.2015.46020 
ranged between $47,153 €$ and $220,117 €$ according to the range of services used by the clients, which translates into a percentage of estimated cost reduction on yearly basis ranged between $3 \%$ and $12.5 \%$ of the whole cost of services used by the studied population. Discussion: The paper suggests the capacity of CAMP to reduce both the over-74 hospitalization rate and use of LTC. Cost analysis also indicates a cost reduction as a consequence of the CAMP implementation. Further studies including a control group and a detailed cost-benefit analysis are needed to check the program sustainability on larger population.

\section{Keywords}

\section{Social Isolation, Hospitalization, Long Term Care Use, Active Monitoring, Social Capital}

\section{Introduction}

Social isolation increases in the over-74 population and it is a risk factor for death and Long Term Care (LTC) use [1]-[4]. In the summer of 2003 the heat wave that hit Southern Europe provoked about 20,000 of unexpected deaths [5] [6], mainly among over-74 citizens living alone. Both risks of institutionalization and hospitalization increase with social isolation [7]-[13]. Social isolation represents an aspect of elderly frailty and it is related to the extension and quality of the individual's relationship network. Frailty is three folds higher among the over74 compared with the 65 - 74 age group, so that the over-74 citizens are a target of interest for screening and prevention program. Despite of the link between higher social isolation and both poor quality of life and use of health services by the elderly, only few programs addressed this issue [14].

The Community-based pro-Active Monitoring Program (CAMP) "Long Live the Elderly", run by the Community of Sant'Egidio in collaboration with the municipality of Rome, is an approach aimed to cope with different components of social isolation. The general aim of CAMP is to increase the social capital of both the community and the individual. The hypothesis is that such a program based on periodical phone calls, strengthening of formal and informal carers' network and home visits in case of need could fight the multiple manifestations of social isolation and improve the elderly quality of life. Moreover, the program aims to reduce inappropriate hospital admissions as well as LTC use by temporarily intensifying the support around the isolated individual during physical, mental, socio-economic or environmental crisis.

CAMP targets all the over-74 residents who are reached by means of the list provided by the municipality of Rome. The citizen receives a letter by the program that describes its activity and communicates that the next step is a telephone call finalized to get his/her consent to be included in the program activities. If the consent is given, the citizen receives a phone number active from 9.00 to 17.00, Monday to Friday that can be reached for specific requests; the program contacts the client at least two times per year and during each environmental emergencies like heat or cold wave. If a client shows a specific request, the program tries to meet it either directly or indirectly involving available formal and/or informal resources. Home visits by the program personnel are also possible especially in case of an emergency (namely a flu that prevents the client to buy food or drugs). A specific aim of CAMP is to identify the frail individuals among the population followed up by the program: frailty is assessed by the Geriatric Functional Evaluation—GFE questionnaire [15] during the first month of care, and bi-annually revised by the social assistant responsible for the specific program area. The frails are the target of intervention aimed to strengthen the social network around them involving formal services and/or informal carers who voluntarily make themselves available for performing one or more tasks.

Each program area, which usually includes from 1000 to 2000 patients, is served by one program unite, composed by a social assistant plus three-five operators according to the number of resident clients. Program operators are trained ad hoc, in order to perform home visits, administer the GFE questionnaire, assess basic physical condition, manage administrative tasks related to the relation of the client with the public administration. They are identified by a personal budge and operate at community level being a reference point in the community for the relation between the client and several actors like other clients/elderly living in the area, dealers, GPs, pharmacists, etc. A computer software supports all the activities. The aim of this paper is to measure the 2011 CAMP 
activity and its impact on client's use of health care services.

\section{Methodology}

An observational cross-sectional study has been carried out to assess CAMP program population use of health service. The independent ethic committee of the University of "Tor Vergata" has approved the study. The setting of the study was the oldest administrative area of CAMP program intervention in Rome (called "Trastevere"), where the activities have been going on for seven years. The percentage of elderly is quite similar to the one observed in the whole town. The Trastevere ageing index is 185 vs. 134 for the entire city population while the dependency index and the socio-economic index are in line with city parameter (our elaboration on municipality data). All data presented in this paper are referred to 2011 and have been analyzed during 2014.

All over-74 citizens resident in the area were included in the program and have been contacted at least two times during 2011 according to the routine CAMP schedule as reported above. Information about acute hospital admissions have been obtained directly from the clients according to the discharge letter. Information about the admission to LTC institution were received by the patients and integrated with an active tracing carried out on the field through contacts with the GP, formal and informal carers in case the patients suddenly disappeared during the follow up.

The observed hospitalization and LTC admission rates have been compared with the expected ones retrieved by the information about the population living in the areas close to the one where CAMP was active. Differences between the expected and the observed rates of acute hospital admissions and institutionalization formed the base for cost-saving calculation. Incidence of the amount saved on the total expected cost of care for CAMP population has been also calculated. Both hospitalization and LTC expected costs have been calculated on the basis of the mean cost of this services reported in literature for the over-74 Lazio region population [16] [17]. The hospitalization costs are based on the Disease-Related Group (DRG) methodology that is used in Italy by the Regions (the administrative body in charge for providing health care) to refund to the hospitals the cost of care provided to the patients. The LTC costs are calculated according to the kind of care and facility: in case of Nursing homes, the cost of care is divided between the Regional Health Authority, which is entitled to pay for the health care, and the patients who is entitled to pay an established amount for services other than health care (e.g. food and accommodation). If the patients cannot pay the fee, the municipality where he is resident must pay for him. The latter case is the most expensive for the public bodies and it is due to not self-sufficient patients who need highly intensive care and are poor. The opposite case is the care provided by a private institution to a self-sufficient individual who prefers not to remain at home: the public body does not support economically this kind of care that is totally out-of-pocket.

The Statistical analysis included T-Test and $\chi$-square test.

\section{Results}

The studied sample is made up by 1408 over-74 citizens followed up during 2011 by CAMP, 867 females (mean age $81.2 \pm 6.3$ ) and 541 males (mean age $79.2 \pm 5.4$ ). One person refused to be included in the program and 17 were not reached by the operators; the cumulative proportion of citizens not included in the program was $1.27 \%$. The cumulative observation time was $1362 \mathrm{p} / \mathrm{y}$; 61 individuals died during 2011 (death rate 4.3\%). More than half of the clients were living with their spouse and/or children (742 subjects - 53.4\%) while $25.4 \%$ (353 subjects) were living alone and the remaining with other family's members; the percentage of the clients living with a paid assistant was $3.9 \%$ (55 subjects).

The total number of phone calls to the elderly citizens during the year was 7643 (5.5 per person/year); 374 phone calls have been done by the clients to CAMP ( 0.27 per person/year). Less than $40 \%$ (555/1408, 39.4\%) received a home visit either because they requested it or because the operators decided to visit the client.

During the year 154 clients (10.9\%) received various helps finalized to accomplish bureaucratic tasks to get subsidies or other needed services. During 2011 Formal Home Care Services by the municipality have been activated for 19 clients (1.4\%); the cumulative number of elderly who received home care services (activated before or during 2011) was 102 (7.25\%) as showed in Table 1.

Specific aim of CAMP is to strengthen the social network around the most isolated subjects. Figure 1 shows people who took part to CAMP social network during 2011. The networks components are individuals who gave availability to perform simple tasks like send a message in case one of the clients is not seen for a couple of 
Table 1. Services provided by CAMP during 2011.

\begin{tabular}{ccc}
\hline & N. of reached client & $\%$ \\
\hline Phone calls & 1390 & 97.7 \\
Bureaucratic support & 154 & 10.9 \\
Home care activation & 19 & 1.4 \\
Cumulative home care & 102 & 7.25 \\
\hline
\end{tabular}

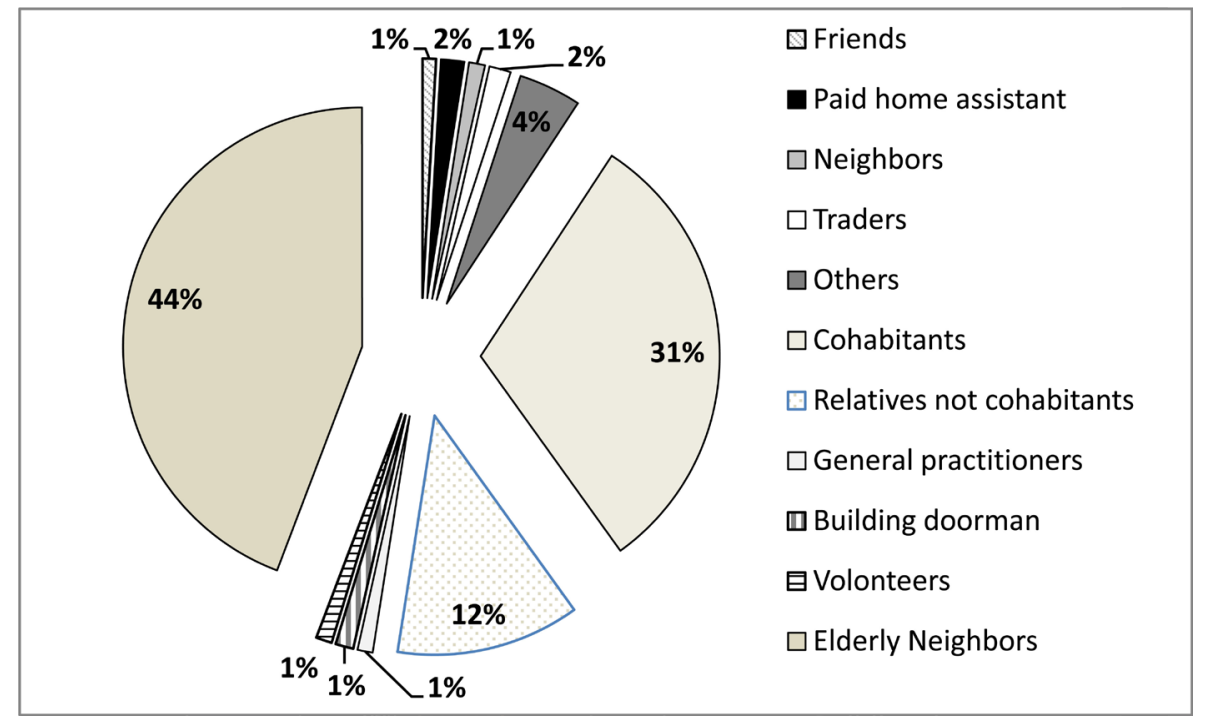

Figure 1. Social networks by components (3538 individuals).

days, or bringing food at home in case of need. Since its beginning CAMP included as actors of the social network, client's cohabitants as well as other persons like elderly neighbors; the latter represent the highest percentage of the network's actors.

The in-patients admission rate stood at 254\%o (357/1, 408; CL95\% $\pm 91 \%$ ) that was lower than 282\%o reported for the over-74 population of Rome [10] and translated into 39 averted hospitalization. Interestingly the percentage of acute care admissions shorter than 2 days out of the total number of admissions was $1.7 \%$ among CAMP's clients compared with $6.3 \%$ and $24.3 \%$ for the over-74 patients living in neighborhoods adjacent to the area where CAMP operates and in the entire Lazio region respectively (data not showed). The LTC admission rate was also reduced among CAMP's clients (9/1,408, 6.6\% CL95\% $\pm 0.8 \%$ vs. 9.7\%o reported for a comparable sample in a similar district of Rome) [18] which translate into 4 averted LTC admissions.

The cost analysis compares average running costs of the program (81 Euros per person/year, Table 2) with the averted costs due to reduction of hospital and LTC admissions as reported in Table 3. From a public perspective the health care costs are counted as the sum of acute admission costs plus the cost of LTC that can varies according to the kind of service and the patient's need. The cost is maximum for a poor not self-sufficient patient who needs the highest level of care and cannot pay: in the case, the patient is admitted to a nursing home and all expenses are totally met by public bodies namely the Regional Health Service and the Municipality. Partially self-sufficient patients are not admitted to nursing homes and they must meet their own expenses for the residential care services provided by other LTC services. The final cost balance showed the estimated averted cost for CAMP's clients ranging between 50,631 $€$ and 223,495 $€$ per year. Taking into consideration the estimated total cost of care for the whole sample, the percentage of saving ranges from $3 \%$ to $12.5 \%$.

\section{Discussion}

The paper shows the impact of CAMP on reduction of both hospitalization and LTC services used by the over74 citizens. It is likely that the reduction of the use of services is a consequence of the social capital increase achieved by the program. 
Table 2. CAMP cost.

\begin{tabular}{cc}
\hline CAMP cost $(\boldsymbol{\epsilon})-\mathbf{1 4 0 8}$ clients & $\boldsymbol{€}$ \\
Capital cost & 30,000 \\
Equipment & 30,000 \\
Headquarter refreshment & 60,000 \\
Total capital cost & \\
Running cost & 4000 \\
Headquarter rent & 75,600 \\
Operator (€ 2100 per 36 person/months) & 8400 \\
Clerk (€ 2100 per 4 person/month) & 16,800 \\
Social Assistant (€ 2800 per 6 person/months) & 5000 \\
IT Technician (€ 2500 per 2 person/month) & 4000 \\
Administrative overhead & $\mathbf{1 1 3 , 8 0 0}$ \\
Total running cost & $\mathbf{8 1}$ \\
\hline
\end{tabular}

Table 3. Averted cost (public perspective).

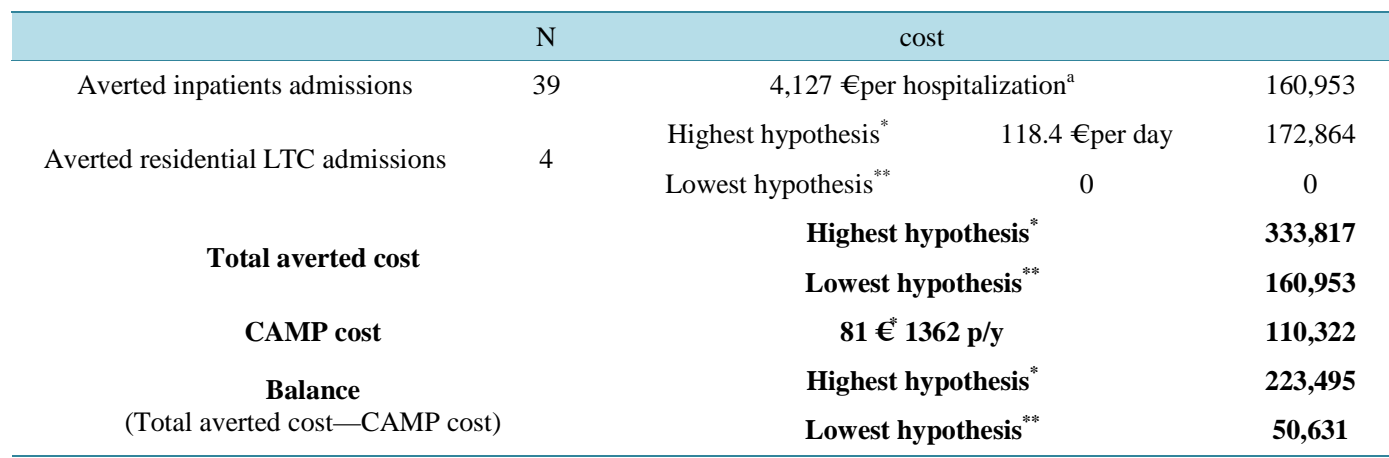

${ }^{a}$ Mean cost per over-74 patients admissions at national level. * All the LTC admissions are severely not self-sufficient patients who need the highest level of care in nursing homes and are totally paid by the public bodies (Regional Health Service and Municipality).

${ }^{* *}$ All the LTC admissions are self-sufficient patients who live in residential facilities for aged completely paid by the clients.

Intervention based on frailty and focused on increasing the individuals' social capital could affect positively the health care services use. The integration of health and social care is the key to manage the care demand generated by the older adults. In fact, socio-economic deprivation is often related to higher rates of in-hospital admissions while integrated primary care program is showed to reduce the number of accesses to the emergency departments and increase the planned hospitalization [19]-[21]. A study recently published suggests a very strong relation between hospital re-admission rate and economic and health factors related to hospital location like the employment levels, the number of general practitioners, and the nursing home quality [22]. The low socio-economic status and social isolation are associated to the elderly in-patients admission due to Ambulatory Care Sensitive conditions [23]. Community programs based on home visits and periodical multidimensional evaluation are also able to reduce the institutionalization rate among the frail elderly [19]. Interventions based on frailty assessment and social capital increase seem to reduce the number of inappropriate elderly hospitalizations and institutionalizations. The issue is delicate as it is reported by Longman and colleagues: "The factors underlying frequent and/or potentially avoidable admissions are numerous and complex. Identifying strategies to improve services or interventions for this group requires understanding patient, career and service providers' perspectives. Improving accessibility of services is also complex, and includes consideration of patients' social, emotional and psychological ability and willingness to use services as well as those services being available and accessed". However, most of the cited papers reported the impact of medical/nursing intervention on the use of health care. CAMP approach is based mostly on a pro-active social intervention, and supports the hypothesis of a benefit for the entire health and social system due to the detection, and follows up of frailty individuals joined to 
a pool of intervention addressed to prevent the negative consequences of frailty. Similarly, in Denmark Vass and colleagues reported a reduced nursing home admission rates for a sample of 80 -year-old people followed up by a pool of home visitors trained for recognizing early manifestation of common diseases [24]. However, the impact of this kind of program is still controversial [25]-[28]. Recently a very large review did not observe any positive impact of home visit programs on hospitalization or independent living even if the authors cannot exclude this impact due to the poor quality of the analyzed data [29]. A previous review assessed the impact of home visits programs quality indicators, namely frequency of visits and use of multidimensional functional assessment tool, and showed the positive impact of some of them on the Nursing Home admission rate and functional decline [24]-[30]. The case manager intervention is also correlated with better quality of life and decrease of the unplanned hospitalizations and Emergency Department (ED) accesses [31].

Quality of intervention at home is a key point to achieve results on health care demand generated by either acute or chronic disease. CAMP joins home visits with the active tracing and monitoring of the citizens and the strengthening/setup of a social network made up by formal and informal careers around the very frail. This is something new, at least for authors' knowledge, in the international overview and it is likely to confer to the program an increased capacity of managing the demand of care. As noted by Sintonen \& Pehkonen: “...social networks and well-being can decrease care needs, and supportive actions should be targeted to avoid loneliness and social isolation so that the informal network could be applied as an aspect of care-giving...” [32]. The lower proportion of admission shorter than two days observed among CAMP's clients suggests a decreased recourse to ED for diseases that do not need hospitalization: this is an indirect marker of the improved appropriateness of care demand. The impact of social capital on the inappropriate use of acute care services is not easy to be highlighted, even if the compactness of social network can be the key point. The role played by the informal actors in the network and the capacity of the program of networking formal and informal individuals and private/public bodies represent the added value of the program. CAMP allows relevant cost saving by managing the demand of care; Kono et al. stated something similar in an interesting randomized controlled trial published in 2013 [33]. The cost saving was correlated to both the decreased number of hospitalization and the use of outpatient care. Cost saving is often observed in studies focused on the efficacy of home visits as well as the improvement in quality of life and clinical outcomes [34].

Since the comparisons about admission rates are based on literature data, the lack of a control group is the main limitation of this study. Moreover, the main sources of data on use of hospital care and LTC services were the clients that could potentially lead to missing information especially in case of sudden health status changes. However, the results of the study suggest that this kind of program could improve the appropriateness and reduce the costs of elderly care.

In conclusion, the paper highlights the role played by an innovative community-based program targeting the over-74 citizens and aims to identify and support the frails. Further studies including a control group and more detailed cost-benefit analysis are needed to size the impact of similar program on the use of health and social services. However, the implementation of such a program, especially in urban contexts, seems to be highly recommendable, because of its capacity to increase the social capital and focus on the most isolated elderly who probably will not reach the services even if they need urgently to be helped.

\section{References}

[1] Steptoe, A., Shankar, A., Demakakos, P. and Wardle, J. (2013) Social Isolation, Loneliness, and All-Cause Mortality in Older Men and Women. Proceedings of the National Academy of Sciences of the United States of America, 110, 57975801. http://dx.doi.org/10.1073/pnas.1219686110

[2] Pantell, M., Rehkopf, D., Jutte, D., Syme, S.L., Balmes, J. and Adler, N. (2013) Social Isolation: A Predictor of Mortality Comparable to Traditional Clinical Risk Factors. American Journal of Public Health, 103, 2056-2062. http://dx.doi.org/10.2105/AJPH.2013.301261

[3] Holt-Lunstad, J., Smith, T.B. and Layton, J.B. (2010) Social Relationships and Mortality Risk: A Meta-Analytic Review. PLoS Medicine, 7, e1000316. http://dx.doi.org/10.1371/journal.pmed.1000316

[4] Kuluski, K., Williams, A.P., Laporte, A. and Berta, W. (2012) The Role of Community-Based Care Capacity in Shaping Risk of Long-Term Care Facility Placement. Healthcare Policy, 8, 92-105. http://dx.doi.org/10.12927/hcpol.2012.23023

[5] Conti, S, Meli, P., Minelli, G., Solimini, R., Toccaceli, V., Vichi, M., et al. (2005) Epidemiologic Study of Mortality 
during the Summer 2003 Heat Wave in Italy. Environmental Research, 98, 390-399.

http://dx.doi.org/10.1016/j.envres.2004.10.009

[6] Fouillet, A., Rey, G., Laurent, F., Pavillon, G., Bellec, S., Guihenneuc-Jouyaux, C., et al. (2006) Excess Mortality Related to the August 2003 Heat Wave in France. International Archives of Occupational and Environmental Health, 80, 16-24. http://dx.doi.org/10.1007/s00420-006-0089-4

[7] Nishino, Y., Gilmour, S. and Shibuya, K. (2015) Inequality in Diabetes-Related Hospital Admissions in England by Socioeconomic Deprivation and Ethnicity: Facility-Based Cross Sectional Analysis. PLoS One, 10, e0116689. http://dx.doi.org/10.1371/journal.pone.0116689

[8] Reid, F.D.A., Cook, D.G. and Majeed, A. (1999) Explaining Variation in Hospital Admission Rates between General Practices: Cross Sectional Study. BMJ, 319, 98-103. http://dx.doi.org/10.1136/bmj.319.7202.98

[9] Majeed, A., Bardsley, M., Morgan, D., O’Sullivan, C. and Bindman, A.B. (2000) Cross Sectional Study of Primary Care Groups in London: Association of Measures of Socioeconomic and Health Status with Hospital Admission Rates. BMJ, 321, 1057-1060. http://dx.doi.org/10.1136/bmj.321.7268.1057

[10] Rapp, K., Rothenbacher, D., Magaziner, J., Becker, C., Benzinger, P., König, H.H., Jaensch, A. and Büchele, G. (2015) Risk of Nursing Home Admission After Femoral Fracture Compared With Stroke, Myocardial Infarction, and Pneumonia. Journal of the American Medical Directors Association, 16, 715.e7-715.e12. http://dx.doi.org/10.1016/j.jamda.2015.05.013

[11] Newall, N., McArthur, J. and Menec, V.H. (2015) A Longitudinal Examination of Social Participation, Loneliness, and Use of Physician and Hospital Services. Journal of Aging and Health, 27, 500-518. http://dx.doi.org/10.1177/0898264314552420

[12] Martinez-Reig, M., Ahmad, L. and Duque, G. (2012) The Orthogeriatrics Model of Care: Systematic Review of Predictors of Institutionalization and Mortality in Post-Hip Fracture Patients and Evidence for Interventions. Journal of the American Medical Directors Association, 13, 770-777. http://dx.doi.org/10.1016/j.jamda.2012.07.011

[13] McCann, M., Grundy, E. and O’Reilly, D. (2014) Urban and Rural Differences in Risk of Admission to a Care Home: A Census-Based Follow-Up Study. Health \& Place, 30, 171-176. http://dx.doi.org/10.1016/j.healthplace.2014.09.009

[14] Health Quality Ontario (2008) Social Isolation in Community-Dwelling Seniors: An Evidence-Based Analysis. Ontario Health Technology Assessment Series, 8, 1-49.

[15] Scarcella, P., Liotta, G., Marazzi, M.C., Carbini, R. and Palombi, L. (2005) Analysis of Survival in a Sample of Elderly Patients from Ragusa, Italy on the Basis of a Primary Care Level Multidimensional Evaluation. Archives of Gerontology and Geriatrics, 40, 147-156. http://dx.doi.org/10.1016/j.archger.2004.07.004

[16] Lazio, R. (2013) Regione Lazio. Decreto del Commissario ad Acta n.101/2013. BUR No. 32.

[17] Ministero della salute, Dipartimento della Programmazione e dell’Ordinamento del Servizio Sanitario Nazionale. Dir. Gen. della Programmazione sanitaria. Ufficio VI. Rapporto SDO 2011. www.salute.gov.it/ricoveriOspedalieri/ricoveriOspedalieri.jsp

[18] Sergio, G. and Tenna, M. (2005) Andamento della disabilità nella popolazione anziana di un distretto sanitario di Roma: Valutazione del carico assistenziale. Geriatria Extraospedaliera, 4, 45-47.

[19] Stuck, A.E., Minder, C.E., Peter-Wüest, I., Gillmann, G., Egli, C., Kesselring, A., Leu, R.E. and Beck, J.C. (2000) A Randomized Trial of In-Home Visits for Disability Prevention in Community-Dwelling Older People at Low and High Risk for Nursing Home Admission. Archives of Internal Medicine, 160, 977-986. http://dx.doi.org/10.1001/archinte.160.7.977

[20] de Stampa, M., Vedel, I., Buyck, J.F., Lapointe, L., Bergman, H., Beland, F. and Ankri, J. (2014) Impact on Hospital Admissions of an Integrated Primary Care Model for Very Frail Elderly Patients. Archives of Gerontology and Geriatrics, 58, 350-355. http://dx.doi.org/10.1016/j.archger.2014.01.005

[21] Herrin, J., St. Andre, J., Kenward, K., Joshi, M.S., Audet, A.M.J. and Hines, S.C. (2015) Community Factors and Hospital Readmission Rates. HSR, 50, 20-39.

[22] Longman, J.M., Rolfe, M.I., Passey, M.D., Heathcote, K.E., Ewald, D.P., Dunn, T., Barclay, L.M. and Morgan, G.G. (2012) Frequent Hospital Admission of Older People with Chronic Disease: A Cross Sectional Survey with Telephone Follow-Up and Data Linkage. BMC Health Services Research, 12, 373. http://dx.doi.org/10.1186/1472-6963-12-373

[23] Longman, J.M., Singer, J.B., Gao, Y., Barclay, L.M., Passey, M.E., Pirotta, J.P., et al. (2011) Community Based Service Providers' Perspectives on Frequent and/or Avoidable Admission of Older People with Chronic Disease in Rural NSW: A Qualitative Study. BMC Health Services Research, 11, 265. http://dx.doi.org/10.1186/1472-6963-11-265

[24] Vass, M., Avlund, K., Siersma, V. and Hendriksen, C. (2009) A Feasible Model for Prevention of Functional Decline in Older Home-Dwelling People-The GP Role. A Municipality Randomized Intervention Trial. Family Practice, 26, 56-64. http://dx.doi.org/10.1093/fampra/cmn094 
[25] Huss, A., Stuck, A.E., Rubenstein, L.Z., Egger, M. and Clough-Gorr, K.M.J. (2008) Multidimensional Preventive Home Visit Programs for Community-Dwelling Older Adults: A Systematic Review and Meta-Analysis of Randomized Controlled Trials. The Journals of Gerontology Series A: Biological Sciences and Medical Sciences, 63, $298-307$. http://dx.doi.org/10.1093/gerona/63.3.298

[26] Meinck, M., Lübke, N., Lauterberg, J. and Robra, B.P. (2004) Preventive Home Visits to the Elderly: Systematic Review of Available Evidence. Gesundheitswesen, 66, 732-738. http://dx.doi.org/10.1055/s-2004-813779

[27] Hébert, R., Robichaud, L., Roy, P.M., Bravo, G. and Voyer, L. (2001) Efficacy of a Nurse-Led Multidimensional Preventive Programme for Older People at Risk of Functional Decline. A Randomized Controlled Trial. Age and Ageing, 30, 147-153. http://dx.doi.org/10.1093/ageing/30.2.147

[28] Bouman, A., van Rossum, E., Evers, S., Ambergen, T., Kempen, G. and Knipschild, P. (2008) Effects on Health Care Use and Associated Cost of a Home Visiting Program for Older People with Poor Health Status: A Randomized Clinical Trial in the Netherlands. The Journals of Gerontology Series A: Biological Sciences and Medical Sciences, 63, 291297. http://dx.doi.org/10.1093/gerona/63.3.291

[29] Tappenden, P., Campbell, F., Rawdin, A., Wong, R. and Kalita, N. (2012) The Clinical Effectiveness and Cost-Effectiveness of Home-Based, Nurse-Led Health Promotion for Older People: A Systematic Review. Health Technology Assessment, 16, No. 20. http://dx.doi.org/10.3310/hta16200

[30] Stuck, A.E., Egger, M., Hammer, A., Minder, C.E. and Beck, J.C. (2002) Home Visits to Prevent Nursing Home Admission and Functional Decline in Elderly People: Systematic Review and Metaregression Analysis. JAMA, 287, 10221028. http://dx.doi.org/10.1001/jama.287.8.1022

[31] Wee, S.L., Loke, C.K., Liang, C., Ganesan, G., Wong, L.M. and Cheah, J. (2014) Effectiveness of a National Transitional Care Program in Reducing Acute Care Use. Journal of the American Geriatrics Society, 62, 747-753. http://dx.doi.org/10.1111/jgs.12750

[32] Sintonen, S. and Pehkonen, A. (2014) Effect of Social Networks and Well-Being on Acute Care Needs. Health \& Social Care in the Community, 22, 87-95. http://dx.doi.org/10.1111/hsc.12068

[33] Kono, A., Kanaya, Y., Tsumura, C. and Rubenstein, L.Z. (2013) Effects of Preventive Home Visits on Health Care Costs for Ambulatory Frail Elders: A Randomized Controlled Trial. Aging Clinical and Experimental Research, 25, 575-581. http://dx.doi.org/10.1007/s40520-013-0128-4

[34] Marek, K.D. and Baker, C.D. (2006) Nurse Home Visit Programs for the Elderly. Annual Review of Nursing Research, 24, 157-178. 